\title{
Electrochemistry and Determination of 1-Naphthylacetic Acid Using an Acetylene Black Film Modified Electrode
}

\author{
Wensheng Huang, Wanyun Qu, and Dazhai Zhu \\ Kev Laboratory of Biological Resources Protection and Ltilization of Hubei Province, Hubei Institute for Kationalities, \\ Enshi 45000, P.R. China. ${ }^{*}$ E-mail: huang_wenshat $163 . \mathrm{com}$ \\ Received January 7, 2008
}

\begin{abstract}
The acety lene black $(\mathrm{AB})$ was dispersed into water in the presence of dihexadecyl hydrogen phosphate (DHP) via ultrasonication. resulting in a stable and well-distributed $\mathrm{AB} / \mathrm{DHP}$ suspension. After evaporation of water. an $\mathrm{AB} / \mathrm{DHP}$ composite film-modified electrode was prepared. The electrochemical responses of $\mathrm{K}_{3}\left[\mathrm{Fe}(\mathrm{CN})_{6}\right]$ at the unmodified electrode. DHP film-modified electrode and AB/DHP film-modified electrode were investigated. It is found that the AB/DHP film-modified electrode possesses larger surface area and electron transfer rate constant. Furthermore. the electrochemical behaviors of I-naphthylacetic acid (NAA) were examined. At the AB/DHP film-modified electrode, the oxidation peak current of NAA remarkably increases. Based on this. a sensitive and convenient electrochemical method was proposed for the determination of NAA. The linear range is in the range from $4.0 \times 10^{-8}$ to $5.0 \times 10^{-6} \mathrm{~mol} \mathrm{~L}^{-1}$. and the detection limit is $1.0 \times 10^{-8} \mathrm{~mol}$ $\mathrm{L}^{-1}$. Finally. this new sensing method was emploỵed to determine NAA in several soil samples.
\end{abstract}

Key Words : Acetylene black (AB), Film modified electrode. 1-Naphthylacetic acid (NAA). Determination

\section{Introudetion}

Acetylene black $(\mathrm{AB})$ is a special kind of carbon black with many fascinating properties such as excellent electric conductivity large surface area. strong adsorptive ability and porous structure. Until now. AB was extensively used in electrochemistry for various purposes such as electric double-layer capacitor. ${ }^{1}$ rapid discharge. ${ }^{23}$ cell cathode ${ }^{4}$ and highly-sensitive determination for sodium nitroprusside. kojic acid ${ }^{6} \mathrm{~Pb}^{2-}{ }^{7}$ 2-chlorophenol. ${ }^{8}$ colchicine, adrenaline ${ }^{101}$ as well as 6-benzy laminopurine (6-BAP). ${ }^{11}$ However to the best of our knowledge the application of $\mathrm{AB}$ film electrode in the sensitive determination of 1-naphthylacetic acid has not been reported.

1-Naphthỵlacetic acid (NAA) is naphthalene derivatives extensively used as plant growth regulators and fungicide on fruits. Consequently. trace amounts in soil may be expected coming from agricultural manipulations. To date. different methods such as spectrofluorimetry, 1:13 phosphorimetry ${ }^{1+15}$ high-performance liquid chromatography (HPLC) ${ }^{16}$ and electrochemistry ${ }^{17}$ were reported for the determination of NAA. Herein. we wish to develop a new electrochemical method with high sensitivity rapid response. good accuracy and low cost for the determination of NAA utilizing the excellent properties of $\mathrm{AB}$. Therefore the insoluble $\mathrm{AB}$ was firstly suspended into water in the presence of a special type of surfactant: dihexadecyl hydrogen phosphate (DHP). V/a continuous ultrasonication, a stable and well-distributed $\mathrm{AB} /$ DHP suspension was obtained. After that an AB/DHP filmcoated electrode was prepared after evaporating the water. The electrochemical behaviors of NAA at the ummodified electrode. DHP film-modified electrode and AB/DHP filmmodified electrode were investigated in detail. From the comparisons. it is very clear that the oxidation peak current of NAA greatly increases. and the oxidation peak potential shifts negatively by $100 \mathrm{mV}$ at the $\mathrm{AB} / \mathrm{DHP}$ film-modified electrode. These phenomena indicate that the AB/DHP filmmodified electrode can remarkably inprove the determining sensitivity of NAA.

\section{Experimental}

Reagents. All reagents were of analytical grade and used directly. $1.00 \times 10^{-2} \mathrm{~mol} \mathrm{~L}{ }^{-1}$ stock solution of NAA was prepared by dissolving NAA (Signa) into ethanol. Working solutions were prepared by appropriate dilutions with ethanol. Acetylene black (purity $>99.99 \%$ ) was purchased from STREM Chemicals (USA). Dihexadecyl hydrogen phosphate (DHP) was purchased from Fluka (Fluka chime AG Buchs)

Instruments. All the electrochenical measurements were carried out using a CHI $830 \mathrm{~B}$ Workstation (CH Instnuments. USA). A conventional three-electrode system. consisting of an $\mathrm{AB}$ film modified glassy carbon working electrode. a saturated calomel reference electrode (SCE) and a platinum wire auxiliary electrode. was employed.

Preparation of AB film-modified electrode. $10.0 \mathrm{mg}$ of $\mathrm{AB}$ and $10.0 \mathrm{mg} \mathrm{DHP}$ were added into $10.0 \mathrm{~mL}$ of redistilled water and then sonicated for $30 \mathrm{~min}$. resulting in a black and homogeneous $\mathrm{AB} / \mathrm{DHP}$ suspension. Prior to coating. the glassy carbon electrode (GCE, $3 \mathrm{~mm}$ in diameter) was polished with $0.05 \mu \mathrm{m}$ aluminum slurry. rinsed thoroughly with re-distilled water and finally sonicated in redistilled water for $2 \mathrm{~min}$. After that $10.0 \mu \mathrm{L}$ of $\mathrm{AB} / \mathrm{DHP}$ suspension was added on the clean GCE surface and dried under an IR lamp. The DHP film-modified GCE was prepared by the same procedure as explained above. but without $\mathrm{AB}$

Analytical procedure. Unless otherwise stated. $\mathrm{pH} 3.6$ 
HAc-NaAc buffer $\left(0.1 \mathrm{~mol} \mathrm{~L}^{-1}\right)$ was used as the supporting electrolyte for NAA determination. The accumulation step was carried out under open-circuit while stirring the solution for $5 \mathrm{~min}$. After that. the differential pulse voltanmogranis from 0.50 to $1.20 \mathrm{~V}$ were recorded after 10 -s quiescence. and the peak current at $1.06 \mathrm{~V}$ was measured for NAA.

\section{Results and Discussion}

Electrochemical properties of $\mathrm{AB} / \mathrm{DHP}$ film-modified GCE. The electrochemical properties of $\mathrm{AB} / \mathrm{DHP}$ filmmodified $\mathrm{GCE}$ were investigated using $\mathrm{K}_{3}\left[\mathrm{Fe}(\mathrm{CN})_{6}\right]$ as electrochemical probe. Figure I shows the cyclic voltammograms of $5.0 \times 10^{-3} \mathrm{~mol} \mathrm{~L}^{-1} \mathrm{~K}_{3}\left[\mathrm{Fe}(\mathrm{CN})_{6}\right]$ in $1.0 \mathrm{~mol} \mathrm{~L}-1 \mathrm{KCl}$ solution at the unmodified GCE, DHP film-modified GCE and $\mathrm{AB} / \mathrm{DHP}$ film-modified GCE. At the unmodified GCE (curve a). a pair of redox peak is observed for $\mathrm{K}_{3}\left[\mathrm{Fe}(\mathrm{CN})_{6}\right]$. However, the peak currents obviously decrease at the DHP film-modified GCE (curve b). DHP can form a perfect film on GCE surface and blocks the electron transfer of $\mathrm{K}_{3}\left[\mathrm{Fe}(\mathrm{CN})_{6}\right]$. Thus, the peak currents show remarkable decline. At the AB/DHP film-modified GCE (curve c), the oxidation and reduction peak currents greatly increase compared with those at the unmodified GCE and DHP filmmodified GCE. Furthermore, the electrochenical responses of $\mathrm{K}_{j}\left[\mathrm{Fe}(\mathrm{CN})_{6}\right]$ under different scan rates were examined. It is found that the peak currents is proportional to the square root of scan rate, suggesting that the electrode process of $\mathrm{K}_{3}\left[\mathrm{Fe}(\mathrm{CN})_{6}\right]$ is diffusion control. According to the RandlesSeveik equation. higher peak current means larger surface area. Otherwise, the oxidation peak potential $\left(E_{\mathrm{pi} i}\right)$ shifts negatively and the reduction peak potential $\left(E_{p c}\right)$ shifts positively at the $\mathrm{AB} / \mathrm{DHP}$ film-modified electrode. So. the peak potential separation lowers, indicating that the electrode process of $\mathrm{K}_{3}\left[\mathrm{Fe}(\mathrm{CN})_{6}\right]$ becomes more reversible and the $\mathrm{AB} / \mathrm{DHP}$ film-modified GCE possesses larger standard heterogeneous rate constant. In conclusion, the $\mathrm{AB} / \mathrm{DHP}$ film-modified GCE exhibits unique electrochemical properties. compared with DHP film-modified GCE and unmodified GCE.

Electrochemical behavior of NAA. The electrochemical

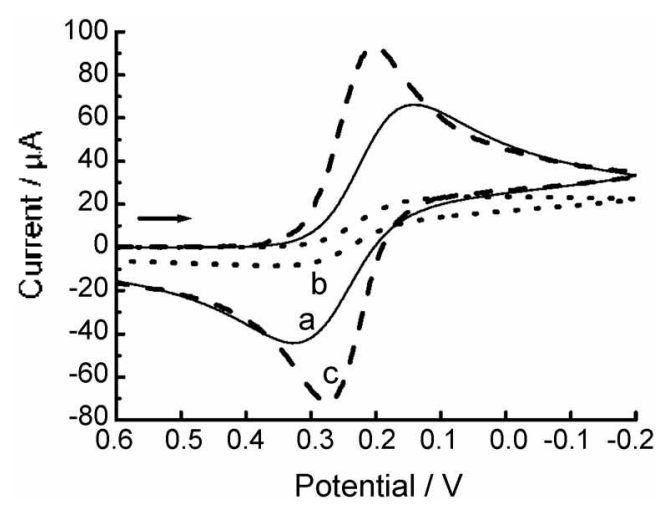

Figure 1. Cyclic voltammograms of $\mathrm{K}_{3}\left[\mathrm{Fe}\left(\mathrm{CN}_{l_{i}}\right]\right.$ at bare $\mathrm{GCE}$ (curve a), DHP tilm-moditied GCE (curve b) and AB/DHP tilmmoditied GCE (curve c). responses of NAA at the unmodified GCE. DHP filmmodified GCE and AB/DHP film-modified GCE were examined in various supporting electrolytes such as $0.01 \mathrm{~mol}$ $\mathrm{L}^{-1} \mathrm{HClO}_{4}$. $\mathrm{pH} 3.6,4.0,4.6,5.0,5.6 \mathrm{HAc}-\mathrm{NaAc}$ buffer $(0.1$ mol L $\left.{ }^{-1}\right)$. pH 6.0. 7.0, 8.0 phosphate buffer $\left(0.1 \mathrm{~mol} \mathrm{~L}^{-1}\right)$. In pH 3.6 HAc-NaAc buffer, the cyclic voltanmetric signals of NAA is relatively better since the oxidation peak shape is best-defined and the peak current is highest. Thus. the electrochemistry and determination of NAA was studied in pH 3.6 HAc-NaAc buffer.

Figure 2 shows the cyclic voltammograms of $1.0 \times 10^{-5}$ mol L ${ }^{-1}$ NAA in pH 3.6 HAc-NaAc buffer at different working electrodes. At the unmodified GCE (curve a), only an oxidation peak is observed at $1.16 \mathrm{~V}$ for NAA during the cyclic sweep between $0.00 \mathrm{~V}$ and $1.30 \mathrm{~V}$. At the DHP filmmodified GCE (curve $b$ ), the $i_{p:}$ of NAA decreases by about $50 \%$. and the oxidation peak potential $\left(\mathrm{E}_{\mathrm{pa}}\right)$ shifts positively. The DHP film on GCE surface is perfect and has poor electric conductivity. So, the mass transport and electron transfer of NAA at the DHP film-modified GCE becomes difficult, resulting in the peak current decline and positive shift of $E_{\mathrm{pl} \text {. }}$. However, the electrochemical responses of NAA at the $\mathrm{AB} / \mathrm{DHP}$ film-modified GCE (curve c) are quite different from those at unmodified and DHP-modified GCEs. It is found that the $i_{\mathrm{Fs}}$ of NAA remarkably increases and the $E_{k i}$ shifts negatively at the $A B / D H P$ film-modified $G C E . A B$ possesses large surface area and strong adsorptive ability. therefore, the $A B / D H P$ film modified GCE shows higher accumulation efficiency toward NAA, resulting in remarkable peak current enhancement. Additionally, the cyclic voltanmograms of $\mathrm{AB} / \mathrm{DHP}$ film-modified $\mathrm{GCE}$ in $\mathrm{pH} 3.6 \mathrm{HAc}-\mathrm{NaAc}$ buffer without NAA are shown in curve (d) for better comparison. and no redox peaks are observed. In brief, it is very clear that the $\mathrm{AB} / \mathrm{DHP}$ film-modified electrode significantly increases the determining sensitivity of NAA because of its unique properties.

Effect of scan rate. The influence of scan rate on the oxidation peak current of NAA at the AB/DHP film-modified GCE was investigated by LSV. As scan rate increasing from 25 to $300 \mathrm{mV} \mathrm{s}^{-1}$, the oxidation peak current of NAA

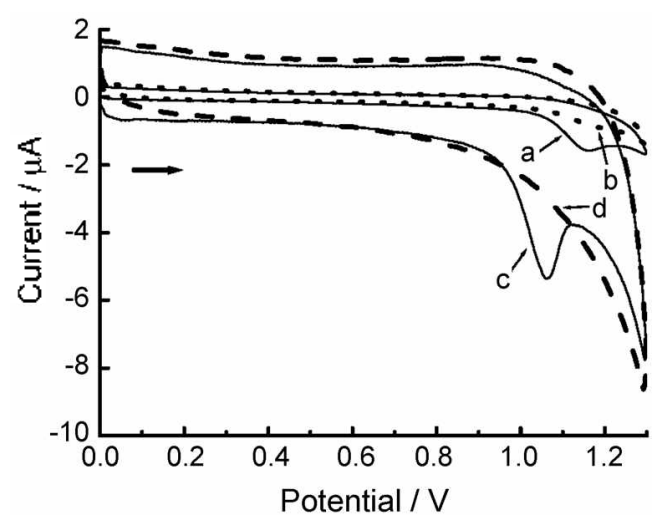

Figure 2. Cyclic voltammograms of $1.0 \times 10^{-5} \mathrm{~mol} \mathrm{~L}^{-1} \mathrm{NAA}$ in $\mathrm{pH}$ 3.6 HAc-NaAc buffer at bare GCE (a), DHP film-modified GCE (b) and AB/DHP film-modified GCE (c). (d): Cyclic voltammograms of AB/DHP tilm-moditied GCE in $\mathrm{pH} 3.6$ butter. 


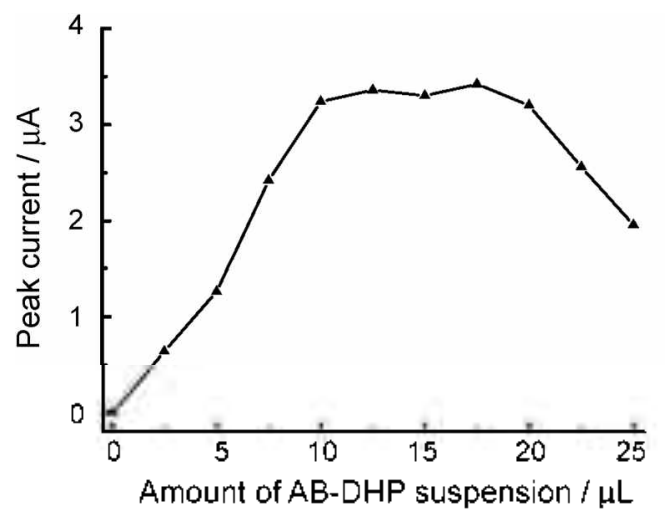

Figure 3. Effect of the amount of ABDHP suspension on the oxidation peak current of $1.0 \times 10^{-6} \mathrm{~mol} \mathrm{~L} \mathrm{~L}^{-1} \mathrm{NAA}$.

increases linearly, revealing that the oxidation of NAA at the $\mathrm{AB} / \mathrm{DHP}$ film-modified GCE is controlled by adsorption.

The amount of $\mathrm{AB} / \mathrm{DHP}$ suspension. The effect of amount of $\mathrm{AB} / \mathrm{DHP}$ suspension that used to modify $\mathrm{GCE}$ surface was examined. Figure 3 demonstrates the variation of oxidation peak current of NAA as a function of the amount of the $\mathrm{AB} / \mathrm{DHP}$ suspension. As the amount of $\mathrm{AB} /$ DHP suspension increases from 0 to $10.0 \mu \mathrm{L}$, the oxidation peak current increases remarkably. However, the oxidation peak current increases slightly as further inproving the volume of $\mathrm{AB} / \mathrm{DHP}$ suspension to $20.0 \mu \mathrm{L}$. If the amount of $\mathrm{AB} / \mathrm{DHP}$ suspension exceeds $20.0 \mu \mathrm{L}$, the oxidation peak current conversely decreases. DHP has low electronic conductivity and can block the mass transport of NAA. So the oxidation peak current of NAA conversely decreases when the amount of $\mathrm{AB} / \mathrm{DHP}$ suspension is too much. In order to shorten the time that consuned to evaporate water and achieve high sensitivity, $10.0 \mu \mathrm{L}$ of $\mathrm{AB} / \mathrm{DHP}$ suspension was used to modify electrode.

Accumulation time. Figure 4 illustrates the relationship between the oxidation peak current of NAA and the accumulation time. When the accumulation time improves form 0.0 to $5.0 \mathrm{~min}$. the oxidation peak current of $1.0 \times 10^{-6} \mathrm{~mol} \mathrm{~L}^{-1}$ of NAA gradually increases at the AB/DHP film-modified GCE. As extending accumulation time the amount of NAA that accumulated at $\mathrm{AB}$ film surface also increases. Without a doubt the oxidation peak current of NAA increases. However the oxidation peak current of NAA almost keeps unchanged as the accumulation time is longer than $5.0 \mathrm{~min}$. indicating that the amount of NAA at the $\mathrm{AB}$ film surface tends to limiting value. Considering both the sensitivity and the working efficiency. $5.0 \mathrm{~min}$ was chosen as the optimal accumulation time.

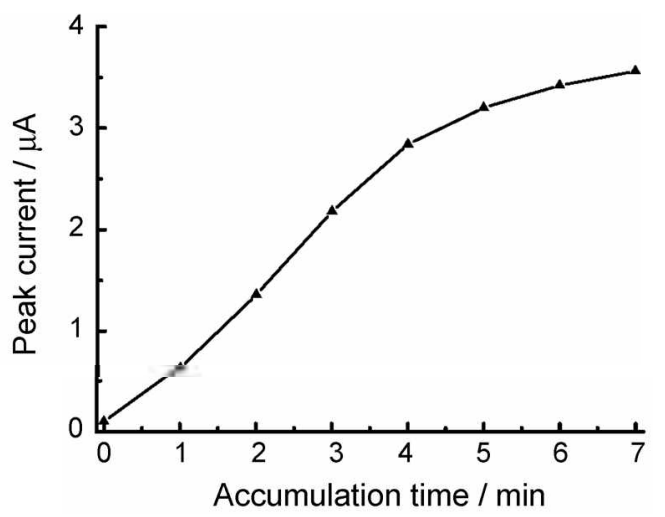

Figure 4 . Influence of acclumulation time on the oxidation peak current of $1.0 \times 10^{-i} \mathrm{~mol} \mathrm{~L}^{-1} \mathrm{NAA}$.

Repeatability and reproducibility. The repeatability was evaluated by successive measuring the same $1.0 \times 10^{-6} \mathrm{~mol}$ $\mathrm{L}^{-1} \mathrm{NAA}$ for 6 times at a single $\mathrm{AB} / \mathrm{DHP}$ modified electrode. After each measurement, the modified electrode was thoroughly rinsed with water, transferred into the blank electrolyte and scanned for 5 cycles to remove any adsorbates. The relative standard deviation (RSD) of $5.6 \%$ indicates excellent repeatability. Additionally, the reproducibility between multiple electrode preparations was estimated by comparing the oxidation peak current of $1.0 \times$ $10^{-6} \mathrm{~mol} \mathrm{~L}^{-1} \mathrm{NAA}$. The RSD is $6.2 \%$ for $10 \mathrm{AB} / \mathrm{DHP}$ modified-GCEs, revealing that the method for preparation of $A B$ / DHP film-modified GCE has good potential applications.

The long-term stability of the $\mathrm{AB} / \mathrm{DHP}$ film-modified GCE was estimated by measuring the current response at a fixed NAA concentration of $1.0 \times 10^{-6} \mathrm{~mol} \mathrm{~L}^{-1}$ over a period of 3 weeks. The AB/DHP film-modified GCE was used daily and stored in air. The experimental results show that the current response only deviates $6.4 \%$, suggesting that the $\mathrm{AB} / \mathrm{DHP}$ film coated GCE possesses long-term stability.

Linear range and limit of detection. The varying of oxidation peak current with concentration was studied using differential pulse voltammetry (DPV). The DPV parameters are: accumulation time $=5$ min: pulse amplitude $=50 \mathrm{mV}$. scan rate $=40 \mathrm{mV} \mathrm{s}^{-1}$, pulse width $=40 \mathrm{~ms}$. It is found that the oxidation peak current of NAA increases linearly with its concentration in the range form $4.0 \times 10^{-8}$ to $5.0 \times 10^{-6} \mathrm{~mol}$ $\mathrm{L}^{-1}(\mathrm{r}=0.998)$. Othervise. the limit of detection was evaluated. and the value is as low as $1.0 \times 10^{-8} \mathrm{~mol} \mathrm{~L}^{-1}$.

Interference. To evaluate the potential interference of foreign species on the determination of NAA at $1.0 \times 10^{-5}$ mol L ${ }^{-1}$. a systematic study was carried out under the aboveoptimized conditions. The peak currents of NAA in the

Table 1. Interference on the determination of $1.0 \times 10^{-5} \mathrm{~mol} \mathrm{~L}^{-1} \mathrm{NAA}$

\begin{tabular}{lc}
\hline \multicolumn{1}{c}{ Foreign species } & Tolerance level/mol $\mathrm{L}^{-1}$ \\
\hline $\mathrm{Ca}^{2-}, \mathrm{Mg}^{2-}, \mathrm{Fe}^{3-}, \mathrm{Zn}^{2+}, \mathrm{Al}^{3+}, \mathrm{Fe}^{3+}, \mathrm{Cu}^{2+}, \mathrm{CO}_{s^{2-}}, \mathrm{SO}_{4}^{2-}$, & $2.0 \times 10^{-3}$ \\
$\mathrm{Ascorbic}$ acid, vitamin $\mathrm{E}$, vitamin $\mathrm{B} 6$, lysine, phenylanianine, glutamicacid & $1.0 \times 10^{-3}$ \\
Tryptophane, cysteine, phenol, 2-11itrophenol, 2-aminophenol & $5.0 \times 10^{-+}$ \\
Indole-3-acetic acid & $2.0 \times 10^{-4}$ \\
\hline
\end{tabular}


Table 2. Detemmination of NAA in soil samples

\begin{tabular}{ccccc}
\hline Sample & $\begin{array}{c}\text { spectrofluorimetry } \\
/ \text { g g g }^{-1}\end{array}$ & $\begin{array}{c}\text { this method } \\
/ \text { ng g }^{-1}\end{array}$ & RSD & Recovery \\
\hline A & 243.1 & 232.4 & $4.2 \%$ & $103.0 \%$ \\
B & 156.2 & 167.5 & $4.6 \%$ & $97.5 \%$ \\
C & 312.6 & 315.4 & $3.9 \%$ & $99.3 \%$ \\
D & 186.4 & 194.2 & $4.1 \%$ & $98.4 \%$ \\
E & 302.8 & 297.4 & $4.4 \%$ & $98.9 \%$ \\
\hline
\end{tabular}

absence and presence of foreign species were measured by DPV. and the error was consequently obtained from the peak current change. The results are listed in Table 1 . It is found that 2000-fold concentrations of $\mathrm{Ca}^{2-}, \mathrm{Mg}^{3+} \cdot \mathrm{Fe}^{3+}, \mathrm{Zn}^{3+}$. $\mathrm{Al}^{3+}, \mathrm{Fe}^{3-}, \mathrm{Cu}^{\hat{2}^{-}}, \mathrm{CO}_{3}{ }^{2-} \cdot \mathrm{SO}_{4}^{\hat{2}^{-}}$. 1000 -fold concentrations of ascorbic acid, vitamin $\mathrm{E}$, vitamin $\mathrm{B} 6$, lysine. pheny lananine. glutanicacid. 500-fold concentrations of tryptophane. cysteine. phenol, 2-nitrophenol, 2-aminophenol, and 200fold concentrations of indole-3-acetic acid, almost do not interfere with the oxidation signal of NAA (error $<10 \%$ ).

Analytical application. This newly-proposed method was used to detect NAA in several soil samples. which collected from the tea garden of Enshi and treated as follows: $5.0 \mathrm{~g}$ of dried soil sample were extracted with $10.0 \mathrm{~mL}$ of absolute ethanol under ultrasonic condition for $30 \mathrm{~min}$. then filtered and the filtrate was diluted with absolute ethanol to $15.0 \mathrm{~mL}$. resulting the soil sample solution. The content of NNA in soil sample was determined by the standard addition method. and the results are listed in Table 2 . Each sample was determined in triplication, and the RSD is below $5.0 \%$. In order to testify the accuracy of this method. the spectrofluorimetric method described in reference ${ }^{1 \hat{3}}$ was also employed to detect the NAA in soil samples. It is found that the results are in good agreement. indicative of good accuracy of this method. In addition. the recovery of NAA was also tested, and the recovery is in the range form $97.5 \%$ to $103.0 \%$. also suggesting that this method has good accuracy.

\section{Conclusion}

Onving to the unique properties of $A B$ such as large surface area and strong adsorptive ability. the $A B$ filmmodified electrode remarkably improves the determining sensitivity of NAA.

Acknowledgments. This work was supported by Open Fund of Key Laboratory of Biologic Resources Protection and Utilization of Hubei Province (PHLHB0803), Hubei Institute for Nationalities.

\section{References}

1. Osaka. T.: Liu, X. J.; Nojima, M. J. Power Somes 1998. 74. 122.

2. Hibino. M.: Kawaoka. H.: Zhou. H. S.: Honma. I. J. Poner Sources $2003.12+143$.

3. Hibino, M.; Kawaoka, H.: Zhou, H. S.; Honma. I. Electrochim Acta 2004. 19. 5209 .

4. Shin. H. C; Cho. W: Jang. H. Electrochim Acta 2006. 52. 1472 .

5. Yang. X. F.: Wang. F.: Hu. S. S. Colloids and Surface B: Biontterfaces 2007. 5H. 60

6. Yang. X. F.: Zhang. H. T. Food Chem. 2007. 102. 1223.

7. Li. G.: Ji. Z. M.: Wu. K. B. Anal. Chin Acta 2006. $577,178$.

8. Sun. D.: Zhang, H. J. Water Research 2006, 40,3069

9. Zhang. H. J. Bioelectrochem 2006, 68, 197.

10. Xie. P. P.: Chen. X. X.: Hu. C. G.: Hu. S. S. Colloids and Surfaces B: Bionterfaces 2006. 48.17.

11. Sur1. D.: Zhang. H. J. Anal. Chim. Acta 2006. 557.64

12. Navalon, A.: Blanc, R.; Vilchez, J. L. Mikrochimica Acta 1997. 126. 33.

13. Vilchez, J. L.: Blanc, R.: Navalon. A. Talonta 1997, $45,105$.

14. Pulgarin. J. A. M.: Lopez. P. F.: Bermejo. L. F. G.: Alfonso. F. M. J. Agr: Food Chem. 2003. 51.6380

15. Long. W. Q. Chinese J. of Anal. Chem. 2005. 33. 1013.

16. Nagayama, T.; Takano, I.: Kobayashi, M.: Tamura. Y.: Tomizawa. S.; Tateishi. Y.: Kimura, N.: Kitayama. K: Saito. K. J. Food Hugienic So. Japan 2003. $4,126$.

17. Lu. S. F. Anal. Lett. 2003. 36. 1523. 